\title{
Forum
}

\section{Ethics and Section 58 of the Mental Health Act (1983)}

\author{
Femi Oyebode, Consultant Psychiatrist, Queen Elizabeth Psychiatric Hospital, \\ Edgbaston, Birmingham B15 2QZ
}

Section 58 is in the part (Part IV) of the Act which is largely concerned with consent to treatment by patients detained on Sections 2, 3, or 37 of the Mental Health Act (1983). It applies to drug treatment if three months or more have elapsed since drugs were first given during the period of detention. It also applies to ECT at any time during the period of detention. Where a patient consents to treatment which comes under Section 58, and which the responsible medical officer (RMO) has proposed and explained to the patient, the RMO is required to certify in writing, on Form 38, that the patient is capable of understanding the nature, purpose and likely effect of the treatment and that the patient has consented (DOH, 1987). The Code of Practice (DOH, 1990) advises that the RMO should indicate on the certificate the drugs proposed, by the classes described in the British National Formulary (BNF), indicating the dosages if they are above BNF advisory maximum limits. The method of administration should also be indicated. This paper will argue that Section 58 in its present form does not strengthen the patient's right to consent to treatment and that the form of words advised in the Code of Practice with respect to Form 38 is faulty in conception.

\section{Informed consent}

The concept of consent to treatment derives from the ethical principle of autonomy. Autonomy can be defined as self-governance in the absence of controlling constraints, such that an individual is able to legislate his or her own norms of conduct and is also able, voluntarily, to fix a course of action. An autonomous individual is thereby conceived of as being a person who deliberates about and chooses plans of actions, and is capable of acting on the basis of such deliberations (Beauchamp \& Childress, 1979). Notions of consent to treatment are justified on the grounds that they promote individual autonomy and as respect for autonomy is accounted high moral value in western tradition, it is often argued that the grounds for violating an individual's right to consent freely to treatment must be very strong indeed.
The key elements of informed consent include the disclosure and comprehension of information, the absence of constraint or coercion, and the competence of the individual to consent. Each of these elements are difficult to define. There are, for example, several standards of disclosure and no consensus on what comprehension means nor how to test for it. The information which is regarded as necessary for a legally valid decision must include a description of the risks, discomforts and side-effects of a proposed treatment, the likely benefits, the alternative treatments and their attendant risks, and the consequences of failure to treat (Meisel et al, 1977). Where a professional practice standard of disclosure is the measure of adequate disclosure, it is assumed that a customary standard exists for a particular situation. The main objection to this standard is that it undermines the patient's autonomy. The reasonable person standard emphasises that risk evaluation belongs to the individual affected and not to the professionals involved. The fact that the reasonable person is a composite or ideal of all reasonable persons shows clearly the difficulty of using this standard of disclosure. The ability of the individual to understand the risks and benefits is used as a proxy for actual comprehension. And, even where comprehension can be demonstrated, acceptance of and belief in the information may be lacking.

The capacity to give informed consent is dependent on the competence of the subject to process information, choose goals and act upon reasonable decisions. There are a number of suggested tests of competence (Roth et al, 1977). The simplest test is the ability to signify a choice. This test focuses on the presence or absence of a decision rather than on the quality of the decision. The simple acceptance or refusal of a proposed treatment without any expression of the reasons for the decision would in this case signify competence. The "reasonable outcome of choice" test emphasises the outcome rather than the mere fact that a decision is reached. The patient who fails to make a decision that is roughly congruent with the decision that a "reasonable" person in like circumstances would make is viewed as 
incompetent. The assumption here is that a person who needs treatment should accept it. There is here an obvious bias towards consenting to medical treatment. The most stringent test is whether the choice is based upon "rational" decisions. To pass this test, the subject would have to demonstrate actual understanding of the issues and be able to calculate riskbenefit ratios. The mere fact that an individual is detained in hospital under a section of the Act does not automatically mean that he or she is incompetent to make decisions in all spheres; he or she still retains such rights as to marriage, voting or making a will.

\section{Ethical problems with Section 58}

The provision of Section 58 acts as a safeguard such that certain forms of treatment shall not be given to a patient unless the patient consents or an independent medical practitioner has certified that either the patient is incapable of giving his or her consent or that the patient should receive the treatment even though he or she has not consented to it (Jones, 1988). The right to refuse treatment is curtailed in the first three months of a detention order. The three month rule judiciously avoids the situation where patients are forcibly detained without receiving any treatment.

The principal problem with Section 58 is that the RMO certifies that the patient is competent and is consenting. This procedure denies the patient the opportunity to demonstrate his or her competence, precisely because it is the RMO who is required to certify that the patient is competent without requiring that the patient signify that his or her authority has been sought and obtained. Consent, as has been described, derives its moral force from the principle of autonomy. This autonomy is most suitably demonstrated by respect for the patient's capacity to act freely and not by being acted for. The current procedure of Section 58 therefore violates this principle which it is in effect meant to support.

There are other difficulties which follow from this principal problem. There are no established procedures for consenting to medication and informal patients do not have to formally signify their consent; mere assent or dissent are recognised as valid decisions in this context. Section 58 therefore creates an anomaly between informal patients, patients recently discharged from compulsory orders, and detained patients for whom Section 58 applies. This anomalous situation does not pertain to Form 39 where the certificate relates specifically to a nonconsenting patient whose competence or autonomy are compromised.

When Mental Health Act Commissioners scrutinise Form 38, the details of the form are compared with drug cards and discrepancies are taken to indicate that the recorded consent does not relate to the treatment being given. The implicit but erroneous assumption is that Form 38 is a consent form. In order to test whether a subject is consenting, the procedure should be to enquire from the subject whether he or she regards him or herself as having consented and then to enquire what he or she believes he or she has consented to. The status of Form $\mathbf{3 8}$ as evidence that a subject has consented to treatment is dubious, in my view.

The guidance which is given in the Code of Practice about how to complete Form 38 is faulty in conception. The disclosure of information which the Code advises is rudimentary. Class of drug, dose only if above BNF limits, and mode of administration are minimal if not meaningless requirements. It could be argued that subjects ought to consent to specified drugs rather than to classes of drugs. The requirement only to specify dosage where it is above BNF limits is misguided in those situations where patients are on combinations of drugs belonging to one class which produce cumulative effects. The intention is clearly to reduce administrative inconvenience. Form 38 is neither a consent form nor an accurate evidence of what is prescribed. It may be argued that it is a certificate of competence to consent but it is not recognised as such by RMOs, Commissioners or patients.

\section{Amendment to Section 58}

Amendments to Section 58 should be guided by the aim of strengthening the rights of long-term detained patients to consent to treatment, thereby increasing their right to autonomous action. The amendments should also lessen the distinction between informal patients, detained patients to whom Section 58 does not apply, and detained patients to whom it does apply. The problems inherent in procedures for formal consent to drug treatments should also be recognised.

With regard to ECT, the requirement to complete Form 38 within the initial three months for all patients detained under Sections 2 or 3, and who have already signified their consent by signing a consent form, is obviously illogical. A document to which a patient has appended his or her signature has more validity than one which is signed solely by an RMO as evidence that authority has been sought. In this case Form 38 is superfluous and should be abrogated.

This paper suggests that the intention of Section 58 will be fully met by a patient's rights document which is activated for all detained patients for whom Section 58 pertains. The document should inform patients of their rights under Section 58, of the obligations of their RMO and of the powers of the RMO to seek a second opinion where necessary if the patient chose to use his or her right to refuse treatment. The role of Commissioners during hospital visits will be to ensure that patients are aware 
of their rights and that they are consenting to treatments given. Form 38 will have no place in this scheme. This amendment will mean that longterm detained patients are treated as autonomous beings with the capacity to understand and make judgements about the need for medication.

\section{References}

Beauchamp, T. L. \& Childress, J. L. (1979) Principles of Biomedical Ethics, 2nd edition. Oxford University Press.
Department of Health (1990) Code Of Practice. London: HMSO.

- (1987) Mental Health Act 1983 Memorandum on Parts I to VI, VIII and X. London: HMSO.

JoNES, R. (1988) Mental Health Act Manual, 2nd Edition. London: Sweet \& Maxwell.

Meisel, A., Roth, L. H. \& Lidz, C. W. (1977) Toward a model of the legal doctrine of informed consent. American Journal of Psychiatry, 134, 285-289.

Roth, L. H., Meisel, A. \& LIDZ, C. W. (1977) Tests of competency to consent to treatment. American Journal of Psychiatry, 134, 279-284.

\section{Response of the Mental Health Act Commission}

The Commission welcomes the opportunity to comment on Dr Oyebode's paper. As a former medical member of the Commission, Dr Oyebode can write with authority on the frustrations felt by many Commissioners when carrying out their statutory obligations to ensure that the requirements of Section 58 of the Act are being met. His paper is particularly opportune considering the recent publication by the Law Commission of its consultation paper No. 129 (Law Commission, 1993).

Dr Oyebode argues that Section 58 does not strengthen the patient's right to consent to treatment and that the advice within the Code of Practice in respect of Form 38 is faulty in conception. He is quite correct to draw attention to the significance placed by the legislation on the certification of consent by the prescribing doctor rather than on the usual requirement that consent should be directly expressed by the patient, for example by signing a consent form.

Although the Mental Health Act does not specifcally refer to the right of the patient to signify consent, it would be unlawful for the responsible medical officer (RMO) to certify consent if consent had not been secured and signified, just as it would be unlawful to use a patient's signed consent form when true consent had been withdrawn. In giving the responsibility of certifying consent to the RMO, the law recognises the particular difficulties faced by detained mentally disordered patients. It does not deny the patient the opportunity to demonstrate consent. Indeed, without that demonstration the certificate is invalid.

The author draws attention to the absence of procedures for establishing and recording consent to medication in informal patients. Consultants could be in difficulties, however, if they accepted the assertion that "mere assent or dissent are recognised as valid decisions in this context". This may not be the position in a court of law.

DrOyebode is not completely correct in stating that Form 39 relates specifically "to a non-consenting patient whose competence and/or autonomy are compromised". It does, of course, also record the authority to administer medicines for the treatment of mental disorder to a competent patient who refuses consent where the treatment should be given.

If there is a discrepancy between the consent certified on Form 38 to a given treatment plan and the treatment plan actually being given then Commissioners are entirely correct to conclude that the recorded consent does not relate to the treatment being given and that there is prima facie evidence that the requirements of Section 58 are not being met. Dr Oyebode's advice that Commissioners should look beyond the correspondence between Form 38 and the treatment card and into the actual consent status of the patient is timely, as is the attention he draws to the latitude which current advice gives in regard to the description of treatment on Form 38. To this extent the minimal requirements suggested by the Code of Practice increase the obligation on the Responsible Medical Officer to ensure that the patient's actual consent is valid at all times.

The conclusion that the RMO's completion of Form 38 is redundant when a detained patient has signed a consent form makes many assumptions about the validity of signed consent forms and the further recommendations place more weight on formal written procedures than perhaps is warranted in a clinical situation, although a patient's rights document might be a useful additional safeguard. The Commission would be interested to learn whether Dr Oyebode's conclusions that the autonomy of detained patients would be better served by abandoning Form 38 is generally supported by the Royal College of Psychiatrists. The frequent discrepancies noted between Form 38 and the actual treatment being given do not inspire confidence that consent issues and patient autonomy generally are currently given sufficient priority.

\section{Reference}

Law Commssion (1993) Mentally Incapacitated Adults and Decision Making. Medical Treatment and Research. Consultation Paper Number 129. London: HMSO. 